\title{
The influence of diet on the quality of faecal fat in patients with and without steatorrhoea
}

\author{
JOAN P. W. WEBB, A. T. JAMES, AND T. D. KELLOCK \\ From the National Institute for Medical Research, Mill Hill, London, and \\ the Department of Gastroenterology, Central Middlesex Hospital, London
}

EDITORIAL SYNOPSIS By the use of gas-liquid chromatography it has been shown that the quality of the faecal fat in individuals without steatorrhoea is little affected by changes in the quality of the dietary fat. Large amounts of non-dietary fatty acids have been identified in the faeces both of patients with and without steatorrhoea. These have been identified as a number of isomers of oleic acid and hydroxystearic acids, particularly 10-hydroxystearic acid.

Factors which influence the amount of fat excreted in the faeces have been extensively studied in both normal people and in patients with steatorrhoea due to various causes. It is usually assumed that faecal fat represents unabsorbed dietary fat, although there is evidence that some is endogenous in origin. The relative importance of these two components can be assessed from examination of the composition as well as of the amount of fat. Few qualitative studies have been carried out, because extremely timeconsuming chemical procedures were necessary to analyse the different fatty acids present in a mixture of fats but such analyses can now be made more easily by gas-liquid chromatography (Anderson and Martin, 1956; James, 1960).

This investigation was undertaken to see what effect a marked change in the quality of the fat consumed would have on the quality of the fat in the faeces. For this purpose butter and corn oil, which differ widely in their fatty acid composition, have been used as the basis of the two different diets used in the study.

\section{METHODS}

The total fats were determined by the method of Anderson, Frazer, French, Gerrard, Sammons, and Smellie (1952) and the free fatty acids by the same method omitting the preliminary hydrolysis. The amount of triglyceride was obtained by subtraction. Details of the chromatographic techniques and of the means used for identification of the individual fatty acids have already been described (James, Webb, and Kellock, 1961). About 20 different fatty acids could be identified in most specimens but for the sake of simplicity only the major components are presented in this paper.

The basic diet contained $11 \mathrm{~g}$. of fat per 24 hours, being the minimal amount that was found reasonable for patients to take. This is described as the low-fat diet. To this basic diet was added either $50 \mathrm{~g}$. of butter or $50 \mathrm{~g}$. of corn oil. Neither butter nor corn oil was used in cooking because of the possibility of undefinable losses due to polymerization. The proportions of the more important fatty acids in butter and corn oil are shown in Figure 1.

A carmine marker was given before the first meal of each new dietary period. All specimens containing any colour from the marker were rejected and a 24-hour

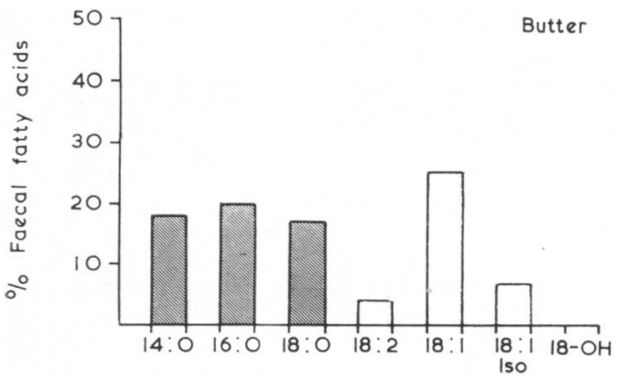

FIG. 1

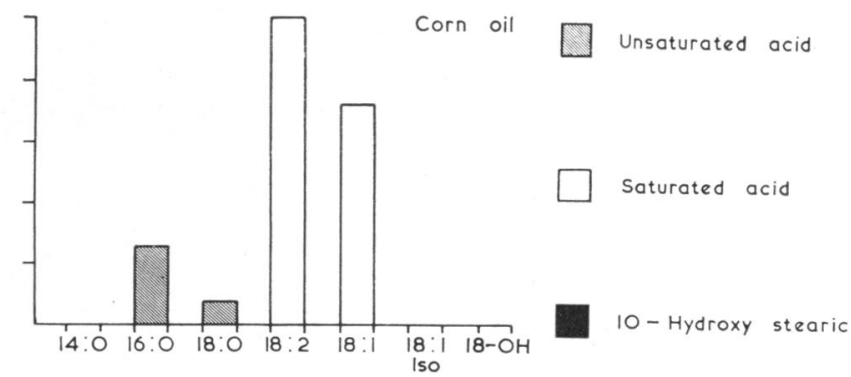

Composition of dietary fat. 
collection of faeces was then made. Another carmine marker was given and the diet changed at the next meal. Again all coloured stools were rejected and a further 24hour collection was made on the new diet. Sometimes three days on the new diet might elapse before all the marker had been excreted. By this method it seems reasonably certain that each of the stools examined truly represented the faeces resulting from a particular diet, while the time that the patients had to spend on these rather unpalatable diets was kept to the minimum. Initially, the stools were passed direct into petroleumether but after examination of a stool before and after remaining at room temperature for seven days had shown almost no qualitative change, the whole 24-hour specimen was collected in a container and then either extracted immediately or stored at $2^{\circ} \mathrm{C}$. until required.

The extracts were saponified, the free fatty acids extracted, dried in ether solution, and esterified in anhydrous methanolic $\mathrm{HCl}$. The esters were analysed with gas-liquid columns of Apiezon $\mathrm{L}$ grease at $200^{\circ} \mathrm{C}$. and in columns of polyethylene glycol adipate at $180^{\circ} \mathrm{C}$. (James, 1960).

\section{RESULTS}

EFFECT OF DIET IN PATIENTS WITHOUT STEATORRHOEA The effect of changing the diet was studied in four patients, none of whom had steatorrhoea at the time of investigation (Fig. 2). Details of the patients are shown in Table I.

With the first three patients, there was no clinical reason to suspect any abnormality of fat excretion. The patient with the non-specific diarrhoea $(\mathrm{Cl})$ had no other signs or symptoms suggestive of malabsorption. The patient (Br) with the postgastrectomy osteoporosis (Table I) who at no time during the present investigations had any evidence of steatorrhoea, had, on one previous occasion, been shown to excrete $11 \mathrm{~g}$. of fat in 24 hours.

From Table I it will be seen that the major part of the faecal fat was hydrolysed, as would be expected in individuals with normal pancreatic function, but in each case the amount in the faeces of both free and bound fatty acids is higher when a corn oil diet was being taken. In fact two of these four patients might have been classified as suffering from steatorrhoea when on the corn oil diet if the limit of normality is taken as an excretion of $5 \mathrm{~g}$. of fat per 24 hours.

Study of the composition of the faecal fat on these two very different diets (Table II) shows that the change of diet produces little variation; on the corn oil diet there is less myristic and stearic acids, and, except in one patient, more linoleic acid than on the butter diet. The changes are small compared with the change in the diet.

There is a considerable difference in the composition of the faecal fat from different individuals on the same diet although there is a close similarity between the composition of the fat from the same patient on different diets. It will also be noted that the composition of the free and the bound fat is, in general, similar in any individual, and where there are differences a change in dietary fat is reflected both in the faccal bound fat and in the faecal free fatty acids. There is, therefore, no suggestion that the triglycerides in the faeces are derived to any greater extent from unhydrolysed dietary fat than are the free fatty acids. It would appear that in the

TABLE I

EXCRETION OF FAECAL FAT IN PATIENTS WITHOUT STEATORRHOEA

\begin{tabular}{|c|c|c|c|c|c|}
\hline \multirow[t]{3}{*}{ Patient } & \multirow[t]{3}{*}{ Diagnosis } & \multicolumn{4}{|c|}{ Faecal Fat per 24 Hours (g.) } \\
\hline & & \multicolumn{2}{|c|}{ Butter Diet } & \multicolumn{2}{|c|}{ Corn Oil Diet } \\
\hline & & Bound & Free & Bound & Free \\
\hline $\begin{array}{l}\text { Wa } \\
\mathrm{Co} \\
\mathrm{Cl} \\
\mathrm{Br}\end{array}$ & $\begin{array}{l}\text { Cerebral thrombosis } \\
\text { Syringomyelia } \\
\text { Non-specific diarrhoea } \\
\text { Post-gastrectomy osteoporosis }\end{array}$ & $\begin{array}{l}0 \cdot 13 \\
0 \cdot 07 \\
1 \cdot 0\end{array}$ & $\begin{array}{l}1.42 \\
0.69 \\
3.7\end{array}$ & $\begin{array}{l}1.8 \\
1.66 \\
0.8\end{array}$ & $\begin{array}{l}2 \cdot 77 \\
6 \cdot 65 \\
5 \cdot 0\end{array}$ \\
\hline
\end{tabular}
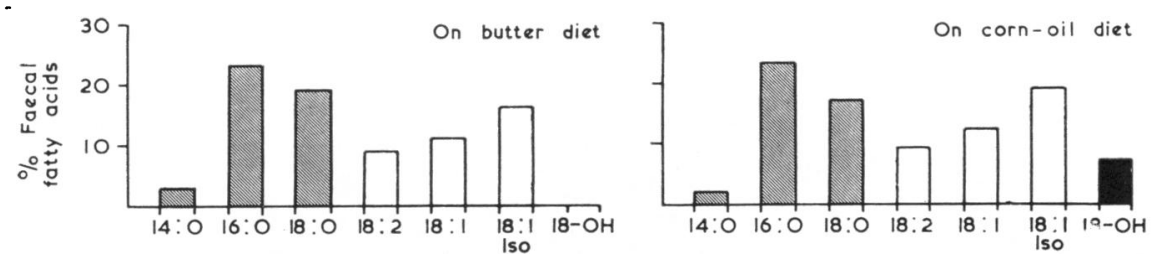

Key, see Fig. 1, page 37.

FIG. 2. Effect of change of diet in faecal triglyceride on a patient without steatorrhoea. 
TABLE II

PROPORTIONS OF FATTY ACIDS AS PERCENTAGE OF TOTAL FATTY ACIDS IN FAECES OF FOUR PATIENTS WITHOUT STEATORRHOEA ON BUTTER AND CORN-OIL DIETS

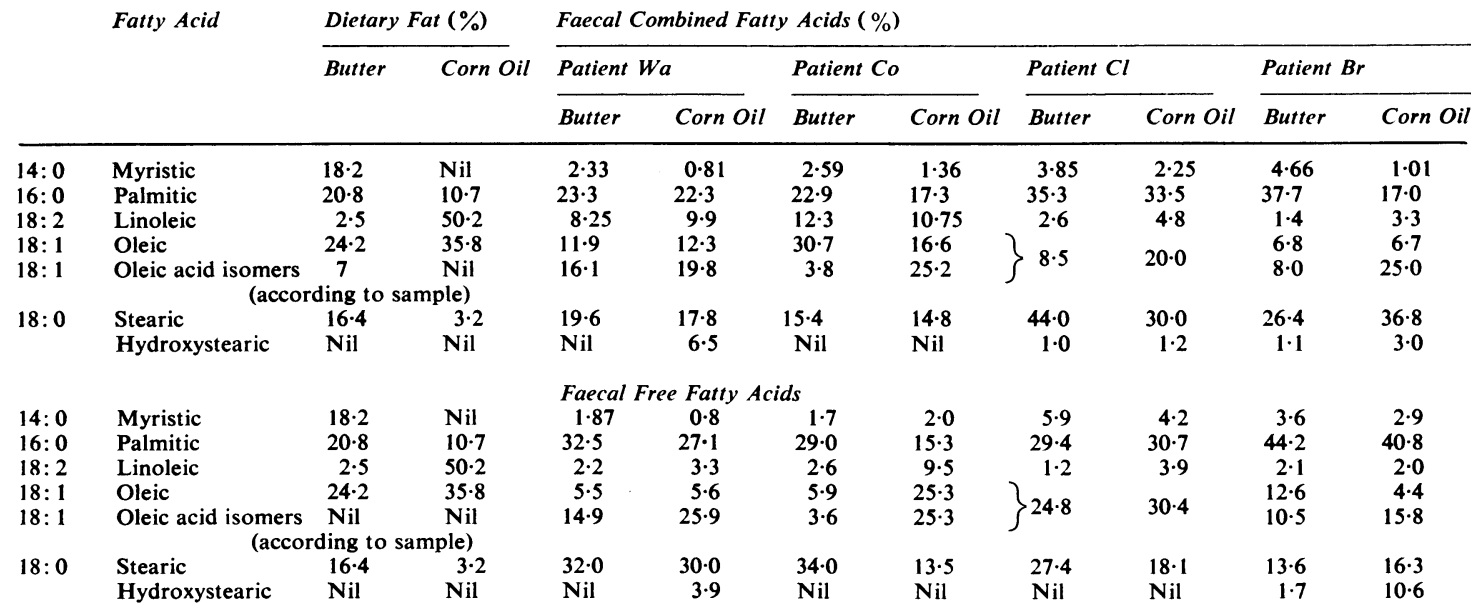

normal the composition of the faecal fat is determined far more by factors peculiar to the individual than by the nature of the ingested fat.

EFFECT OF DIET IN PATIENTS WITH STEATORRHOEA Similar experiments were carried out on three patients with steatorrhoea (Fig. 3 and Table III).

All these three patients had a severe degree of steatorrhoea. Two of them excreted more fat when taking corn oil than when taking butter, and the third showed no change in the amount excreted. The qualitative changes are shown in Table IV.

Unlike the findings in patients without steatorrhoea, it is clear that alteration of the diet made a profound difference to the composition of the faecal fat in these patients with steatorrhoea. This is particularly clear from the alteration in the amount of linoleic acid. This is hardly surprising, as although it has been thought that 'endogenous' fat may be responsible for some of the excessive faecal fat output in these patients, it is known from many studies
TABLE III

EFFECT OF DIET ON FAECAL FAT EXCRETION IN PATIENTS WITH STEATORRHOEA

\begin{tabular}{|c|c|c|c|c|}
\hline \multirow[t]{3}{*}{ Diagnosis } & \multicolumn{4}{|c|}{ Faecal Fat (g. per 24 hr.) } \\
\hline & \multicolumn{2}{|c|}{ Butter Diet } & \multicolumn{2}{|c|}{ Corn Oil Diet } \\
\hline & Bound & Free & Bound & Free \\
\hline \multirow{2}{*}{$\begin{array}{l}\text { Idiopathic steatorrhoea } \\
\text { Post-gastrectomy steatorrhoea }\end{array}$} & $\begin{array}{r}1.5 \\
18.6\end{array}$ & $50 \cdot 1$ & $\begin{array}{l}3 \cdot 2 \\
3.4\end{array}$ & $\begin{array}{l}47 \cdot 3 \\
38 \cdot 8\end{array}$ \\
\hline & $18 \cdot 6$ & $12 \cdot 6$ & $3 \cdot 4$ & $38 \cdot 8$ \\
\hline Idiopathic steatorrhoea & $31 \cdot 8$ & & & \\
\hline
\end{tabular}

with labelled fats that most of the faecal fat in patients with steatorrhoea is unabsorbed dietary fat. These changes are of the same order for both the triglycerides and the free fatty acids.

Of considerably greater interest is the finding, as in the normals, of large amounts of isomers of oleic acid which were not present in the diet and a large amount of unusual fatty acids. Other studies (James et al., 1961) have demonstrated that these
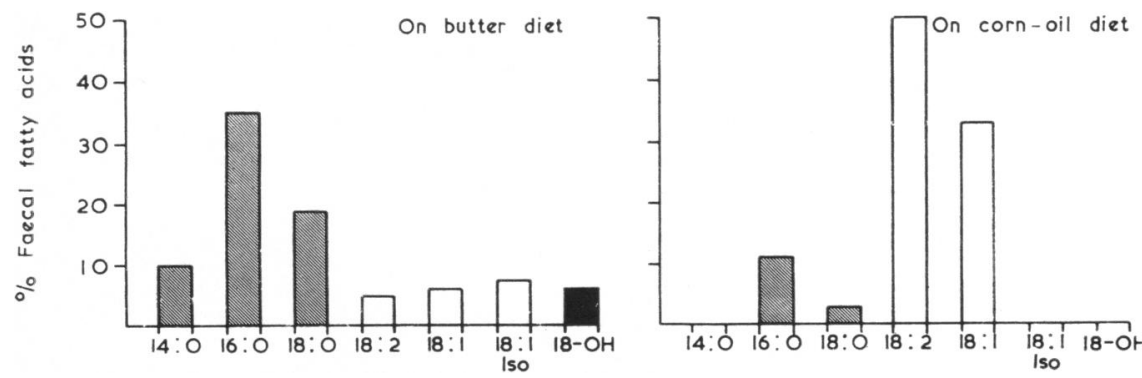

Key, see Fig. I, page 37.

FIG. 3. Effect of change of diet in faecal triglyceride on a patient with steatorrhoea. 
TABLE IV

PROPORTIONS OF FATTY ACIDS AS PERCENTAGES OF TOTAL FATTY ACIDS IN FAECES OF THREE PATIENTS WITH STEATORRHOEA ON BUTTER AND CORN-OIL DIETS

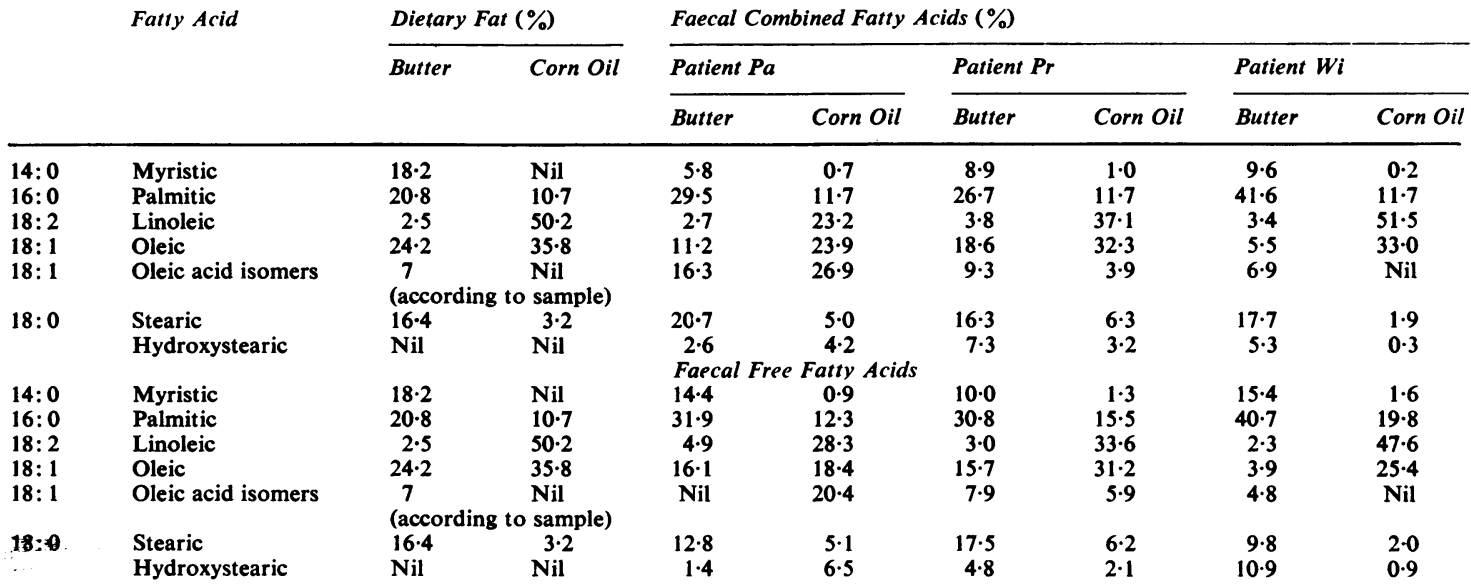

non-dietary octadecenoic fatty acids consisted of a mixture of isomers with the double bond in positions $4,5,6,7,8,9,10,11$, and 12 , approximately half of these isomers possessing the trans-configuration about the double bond. The other unusual fatty acid was shown to be 10-hydroxystearic acid with small amounts of 6-, 7-, 8-, and 9-hydroxystearic acids.

\section{DISCUSSION}

The origin of faecal fat has been a matter for considerable speculation. Sperry (1932) showed that dogs on a fat-free diet excreted an average amount of $219 \mathrm{mg}$. $/ \mathrm{kg}$. $/$ week of fat and that this amount was increased to $615 \mathrm{mg}$. $/ \mathrm{kg}$./week if a bile fistula was formed, presumably due to a failure to reabsorb fat that had been excreted into the lumen of the bowel. After a series of experiments he concluded that not over $40 \%$, and probably much less, consisted of fat incorporated in bacteria. These experiments were confirmed by Pessoa, Kim, and Ivy (1953) who found that ligation of the pancreatic duct also increased the faecal fat loss. These authors considered that about $440 \mathrm{mg}$. $/ \mathrm{kg}$. of fat was daily excreted into the bowel and mostly reabsorbed, possibly $252 \mathrm{mg} / \mathrm{kg}$. of this fat representing desquamated mucosa. Few studies have been carried out in the human but Lewis and Partin (1954) found a fat excretion of between 1 and $3 \mathrm{~g}$. per day in three subjects on a fat-free diet. In a number of cases of patients with steatorrhoea it has been found on occasion that the daily fat output appears to exceed the intake. One such case is included in the present series of a woman with a very severe idiopathic steatorrhoea who excreted $13.5 \mathrm{~g}$. of fat on a diet containing only $11 \mathrm{~g}$., but it must be remembered that it is difficult to carry out accurate balance studies on these very ill patients. The present studies in patients without steatorrhoea show that the nature of the dietary fat appears to have little influence on the composition of the faecal fat. It would appear likely that in patients without steatorrhoea a high proportion of the faecal fat is 'endogenous' in origin.

The overall similarity between the composition of the faecal triglycerides and the free fatty acids in patients both with and without steatorrhoea suggests that in the bowel hydrolysis and resynthesis of triglyceride are both proceeding rapidly and this has been suggested by much other work.

The finding of significant amounts of 10-hydroxystearic acid in the faecal fat of patients with steatorrhoea is of more than academic interest as hydroxy acids occur in a number of purgatives (Table V). Thus, the presence of this fatty acid could be a factor in producing the diarrhoea which, in the great majority of cases, is associated with steatorrhoea.

In subjects with steatorrhoea comparison of the composition of the faecal and dietary fat shows that the sum of the $C_{18}$ acids is roughly constant. It has already been shown (Webb, James, and Kellock, 1961) that these hydroxystearic acids are synthesized by faecal micro-organisms from free stearic acid. These facts suggest that the major differences in composition of dietary fat and faecal fat are due to transformation of unabsorbed fat by the microorganisms in the gut, e.g., by reduction of linoleic acid, oxidation of stearic acid, and syntheses of oleic acid isomers, probably from stearic acid. 
TABLE V

HYDROXY ACIDS IN PURGATIVES

Structure

12-Hydroxy-9-octadecanoic acid

16-Hydroxyoctadecanoic acid

11-Hydroxyhexadecanoic acid

11-Hydroxypentadecanoic acid

12-Hydroxydodecanoic acid
Trivial Name

Ricinoleic acid

Junipric acid

Jalapinolic acid

Convolvulinic acid

Sabinic acid
Source

Castor oil

Castor oil

Jalap resin

Resin from Convolvulus scamnia

Wax from Juniperus sabina
We wish to express our gratitude to Dr. J. Polyzos, Mr. H. Hadaway, and Miss P. B. Wilcox for their great assistance.

\section{REFERENCES}

Anderson, C. M., Frazer, A. C., French, J. M., Gerrard, J. W., Sammons, H. G., and Smellie, J. M. (1952). Coeliac disease: gastro-intestinal studies and the effect of dietary wheat flour. Lancet, 1, 836-842.

- and Martin, A. J. P. (1956). Gas-liquid chromatography: the separation and identification of the methyl esters of saturated and unsaturated acids from formic acid to noctadecanoic acid. Biochem. J., 63 , 144-152.
James, A. T. (1960). Qualitative and quantitative determination of the fatty acids by gas-liquid chromatography. In Methods of Biochemical Analysis, edited by David Glick, vol. 8, pp. 1-60. Interscience Publishers, New York.

- Webb, J. P. W., and Kellock T. D. (1961). The occurrence of unusual fatty acids in faecal lipids from human beings with normal and abnormal fat absorption. Biochem. J., 78, 333-339.

Lewis, G. T., and Partin, H. C. (1954). Fecal fat on an essentially fatfree diet. J. Lab. clin. Med., 44, 91-93.

Pessoa, V. C., Kim, K.S., and Ivy, A. C. (1953). Fat absorption in absence of bile and pancreatic juice. Amer. J. Physiol., 174, 209-218.

Sperry, W. M. (1932). Lipid excretion. VIII. The lipid content of the intestinal mucosa. J. biol. Chem., 96, 759-768.

Webb, J. P. W., James, A. T., and Kellock, T. D. (1961). In Digestion, Absorption Intestinale et Transport des Glycerides chez les Animaux Supérieurs, p. 113. Published by Editions du Centre National de la Recherche Scientifique, Paris.

\section{The December 1962 Issue}

\section{THE DECEMBER 1962 ISSUE CONTAINS THE FOLLOWING PAPERS}

Immunological reactions in gastrointestinal disease: a review K. B. TAYLOR and S. C. TRUELOVE

Larval granulomata in the liver R. A. B. DRURY

Dynamics of the mucosa of the small intestine in idiopathic steatorrhoea B. CREAMER

Faecal stasis in proctocolitis J. E. LENNARD-JONES, M. J. S. LANGMAN, and F. AVERY JONES

The management of fulminant ulcerative colitis N. D. GALlAGHER, S. J. M. GOULSTON, N. WYNDHAM, and SIR WILLIAM MORROW

Betamethasone enemata in ulcerative colitis $\mathbf{s}$. G. FLAVELL MATTS

On the site of absorption of fat from the human small intestine BENGT BORGSTRÖM, ARNE DAHLQVIST, and GÖRAN LUNDH

Factors influencing the bromsulphalein retention and its evaluation of bilharzial hepatic fibrosis H. S. BADAWI, A. M. NOMEIR, and R. A. ZAHER

Carcinoma in the gastric remnant after partial gastrectomy for benign ulceration $A$ study of three cases illustrating the diagnostic contribution of exfoliative cytology $\quad$ D. D. GIBBS
17-Ketosteroid and 17-hydroxycorticosteroid excretion in patients with duodenal ulceration A. G. GREEN and C. N. PULVERTAFT

The use of the d-xylose excretion test in children PETER A. CLARK

The role of the pancreas in gastric secretion $B$. N. CATCHPOLE

The motility of the pelvic colon Part II Paradoxical motility in diarrhoea and constipation ALASTAIR M. CONNELL

The electrophoresis of human gastric juice $D$. W. PIPER, MIRJAM C. STIEL, and JANET E. BUILDER

Part I In normal controls

Part II In patients with gastric ulcer

Part III In pernicious anaemia patients

Methods and techniques

An evaluation of the gastroduodenal fibrescope WILLIAM BURNETT

The use of telemetering capsules in disorders of the alimentary tract A. N. SMITH and M. RIDGWAY Part 1 A technique of recording pressure changes Part II The application to the study of human gastrointestinal motility

Index to volume 3

Copies are still available and may be obtained from the PUBLISHING MANAGER, BRITISH MEDICAL ASSOCIATION, TAVISTOCK SQUARE, W.C.I., price 17s. 6D. 